\title{
Gambaran Suhu Inti Tubuh Preanestesi dan Pascaanestesi pada Pasien Sectio Caesarea di Rumah Sakit Dr. Hasan Sadikin Bandung
}

\author{
Nadya Aliza Mulyadi, ${ }^{1}$ Suwarman, ${ }^{2}$ Dedi Fitri Yadi ${ }^{2}$ \\ ${ }^{1}$ Program Studi Kedokteran, Fakultas Kedokteran, Universitas Padjadjaran, Bandung \\ ${ }^{2}$ Departemen Anestesi dan Terapi Intensif, Fakultas Kedokteran, Universitas Padjadjaran/Rumah \\ Sakit Dr. Hasan Sadikin Bandung
}

\begin{abstract}
Abstrak
Perubahan suhu inti tubuh dapat terjadi pada pasien perioperatif dan disebabkan oleh beberapa faktor seperti jenis operasi, jenis anestesi yang diberikan, durasi operasi, dan tata laksana yang dilakukan pascaoperasi, begitu pula pada kondisi pemulihan suhu inti tubuh. Penelitian ini bertujuan mengetahui gambaran umum suhu inti tubuh preanestesi dan pascaanestesi pada pasien sectio caesarea di Rumah Sakit Dr. Hasan Sadikin Bandung.Penelitian ini dilakukan kepada pasien peripartum yang menjalani operasi sectio caesarea pada September hingga Oktober 2018 di Central Operation Theater dan Ruang Pemulihan Rumah Sakit Dr. Hasan Sadikin Bandung menggunakan metode observasional dengan pendekatan potong lintang secara total sampling, jumlah sampel didapatkan 47 orang. Suhu inti tubuh diukur sebelum preanestesi dan pascaanestesi menggunakan termometer timpanik. Data yang terkumpul dianalisis secara deskriptif dengan hasil berupa frekuensi dan persentase yang disajikan dalam bentuk tabel atau grafik. Hasil penelitian ini menunjukkan bahwa terdapat perubahan suhu inti tubuh dengan rerata penurunan $0,15^{\circ} \mathrm{C}$, yakni terdapat penurunan sebanyak 63,8\% dan peningkatan sebanyak 36,2\%. Simpulan, semua pasien pada penelitian ini mengalami perubahan suhu inti tubuh. Lebih banyak pasien yang mengalami penurunan suhu inti tubuh dibanding dengan peningkatan suhu inti tubuh. Pengendalian faktor eksternal mengurangi risiko penurunan suhu inti tubuh berlebih.
\end{abstract}

Kata kunci: Anestesi umum, anestesi regional, peningkatan suhu, sectio caesarea, suhu inti tubuh

\section{Pre-Anesthesia and Post-Anesthesia Core Body Temperature of Patients Underwent Caesarean Section in Dr. Hasan Sadikin General Hospital Bandung}

\begin{abstract}
Changes in core body temperature can occur to anyone, especially to perioperative patients. Perioperative patient's core body temperature change is caused by various factors such as the type of surgery, type of anesthesia used, duration of surgery, postoperative management, and core temperature recovery process. This study was conducted to describe pre-anesthesia and post-anesthesia core body temperature of patients underwent caesarean section in Dr. Hasan Sadikin General Hospital Bandung. This was a cross-sectional observational study on peripartum patients underwent caesarean section during the period between the third week of September to the third week of October 2018 at the Central Operation Theater and Recovery Room of Dr. Hasan Sadikin General Hospital. Sampling was performed using total sampling approach, resulting in 47 subjects. The core body temperature was measured with tympanic thermometer before anesthesia and after anesthesia. Data analysis was carried out descriptively in the form of tables and graphs of frequencies and percentages. Results showed that the core body temperature change with a decrease of $0.15^{\circ} \mathrm{C}$, decreased core body temperature was seen in $63.8 \%$ of the subjects with the remaining $36.2 \%$ experienced an increase in core body temperature. In conclusion, the all subjects in this study experienced changes in core body temperature with a decrease in temperature as the more likely change. Controlling the external factors can reduce the risk of excessive core body temperature decline.
\end{abstract}

Key words: Core body temperature, decrease in temperature, increase in temperature, caesaran section, general anesthesia, regional anesthesia

Korespondensi: Nadya Aliza Mulyadi, S.Ked., Program Studi Kedokteran Universitas Padjadjaran, Jl. Prof. Eykman No. 38 Bandung, Tlpn (022) 2038114,Email: nadya15025@mail.unpad.ac.id 


\section{Pendahuluan}

Suhu inti tubuh merupakan parameter vital tubuh yang diatur oleh hipotalamus dan meliputi organ-organ yang ada di trunkal, sistem saraf pusat, dan otot rangka. Suhu inti tubuh bermanfaat untuk melihat kondisi vital pasien karena suhu inti tubuh pada keadaan normal diproduksi oleh hasil metabolisme jaringan inti tubuh yang berfungsi optimal pada $37^{\circ} \mathrm{C} .{ }^{1}$ Terdapat faktor yang memengaruhi suhu inti tubuh, yaitu jam biologis, jenis kelamin, usia, dan faktor ekstrinsik seperti jenis aktivitas yang dilakukan, paparan suhu ekstrem, dan paparan zat kimia lain. ${ }^{1}$

Suhu inti tubuh mengalami perubahan seperti penurunan akibat pelepasan panas tubuh berlebih, yaitu kurang dari $36^{\circ} \mathrm{C}$ dan peningkatan akibat produksi panas tubuh berlebih hingga lebih dari $37,2^{\circ} \mathrm{C}$. Kondisi tersebut disebabkan oleh gangguan fase termoregulasi, yaitu input aferen, pengaturan pusat, dan respons eferen yang memicu pelepasan panas tubuh. Termoregulasi merupakan mekanisme yang penting dalam mengatur keseimbangan panas tubuh, baik yang diproduksi dari metabolisme maupun panas yang diabsorbsi dari lingkungan dan dilepas ke lingkungan. Metabolisme dalam tubuh terus terjadi dan menghasilkan panas tubuh. Terdapat 4 mekanisme yang terjadi dalam pelepasan panas tubuh, yaitu radiasi, konveksi, konduksi, dan evaporasi. ${ }^{1,2}$ Saat pelepasan panas tubuh terjadi redistribusi panas tubuh dari bagian inti tubuh ke bagian perifer. Redistribusi panas tubuh dari bagian inti ke bagian perifer terjadi sekitar 1 jam. $^{3}$ Karena suhu tubuh perifer mengalami peningkatan maka panas tubuh di perifer akan dilepas ke lingkungan dengan 4 mekanisme pelepasan panas tubuh tersebut.

Perubahan suhu inti tubuh dapat terjadi khususnya pada pasien perioperatif mulai dari persiapan awal operasi hingga pemulihan pascaoperasi. ${ }^{4}$ Perubahan suhu inti tubuh pascaoperatif dapat disebabkan oleh beberapa faktor seperti jenis anestesi yang diberikan, durasi anestesi, indeks massa tubuh (IMT) pasien, dan tata laksana yang dilakukan pascaoperasi. Kondisi pemulihan suhu tubuh inti juga dipengaruhi oleh jenis anestesi yang dilakukan. ${ }^{3-5}$ Jenis anestesi, baik umum maupun regional, dapat memengaruhi suhu inti tubuh dengan menurunkan ambang batas vasokonstriksi dan respons menggigil, serta meningkatkan ambang batas ekskresi keringat. ${ }^{2,3,6,7}$

Proses pelepasan panas tubuh akan terus terjadi selama operasi karena redistribusi panas dari inti ke perifer tubuh. ${ }^{2}$ Pada anestesi umum terjadi vasodilatasi yang menyebabkan aliran panas inti menuju bagian tubuh perifer sehingga menurunkan suhu inti dan meningkatkan suhu perifer tubuh. Penurunan suhu inti ini akan mencapai fase plateu setelah 3-4 jam pemberian anestesi. Hal ini disebabkan oleh beberapa hal, seperti vasokonstriksi setelah penurunan suhu inti dan mekanisme restriksi dari penyebaran panas metabolik ke bagian inti tubuh untuk menjaga suhu tubuh. ${ }^{2}$ Anestesi regional dapat mengganggu termoregulator pusat yang akan menyebabkan penurunan intensitas maksimal pada respons menggigil yang disebabkan oleh regulasi behavioral yang terganggu. Hal tersebut menyebabkan pasien dengan anestesi regional tidak menyadari bahwa mereka mengalami hipotermia sehingga sering kali kejadian hipotermia tidak terdeteksi pada pasien dengan anestesi regional. $^{2}$

Persalinan sectio caesarea (SC) adalah metode persalinan operatif yang dilakukan dengan indikasi. Sectio caesarea merupakan operasi yang membutuhkan daerah insisi yang luas dan cairan untuk membersihkan ruang peritoneum. Hal tersebut berpengaruh terhadap perubahan suhu inti tubuh akibat permukaan tubuh pasien yang basah dan lembap sehingga proses redistribusi panas tubuh menjadi lebih cepat. ${ }^{2}$ Standar rerata persalinan sectio caesarea di suatu negara menurut WHO adalah sekitar 5-15 persen per 1.000 kelahiran di dunia. Angka kelahiran dengan sectio caesarea di Indonesia sebesar 9,8\% dari total 49.603 kelahiran sepanjang tahun 2010 hingga 2013. Jawa Baratmenduduki peringkat 17 dari 33 provinsi di Indonesia. ${ }^{8}$ Sectio caesarea umumnya menggunakan 
anestesi regional dan menggunakan obat analgesik seperti morfin yang dapat memicu kejadian hipotermia pada pasien pascaoperasi di ruang pemulihan. ${ }^{9}$ Kejadian hipotermia perioperatif lebih sedikit ditemukan pada pasien sectio caesarea yang diberikan anestesi umum dibanding dengan anestesi regional. Hipotermia pada pasien yang menjalani persalinan sectio caesarea dapat memberikan dampak pada beberapa kondisi neonatus, seperti suhu tubuh, $\mathrm{pH}$ darah arteri, dan skor APGAR. ${ }^{9,10}$ Suhu tubuh neonatus dapat menjadi di bawah batas ambang dan menyebabkan kondisi hipotermia yang akan meningkatkan risiko kematian neonatus. ${ }^{11}$

Tujuan penelitian ini adalah mengetahui gambaran umum suhu inti tubuh preanestesi dan pascaanestesi pasien sectio caesarea di Rumah Sakit Dr. Hasan Sadikin Bandung. Gambaran umum suhu inti tubuh preanestesi dan pascaanestesi pasien sectio caesarea dapat menjadi salah satu bahan evaluasi dari tata laksana perioperatif di Rumah Sakit Dr. Hasan Sadikin Bandung dan untuk mengurangi risiko hipotermia pada pasien perioperatif sectio caesarea.

\section{Subjek dan Metode}

Jenis penelitian ini adalah observasional dengan rancangan penelitian bersifat potong lintang yang dilakukan dengan cara deskriptif melalui pengukuran yang dilakukan terhadap variabel suhu inti preanestesi dan suhu inti pascaanestesi. Subjek penelitian ini adalah pasien peripartum yang menjalani sectio caesarea di Rumah Sakit Dr. Hasan Sadikin Bandung dalam rentang waktu 30 hari pada bulan September-Oktober 2018. Kriteria inklusi subjek penelitian ini adalah pasien peripartum yang setuju untuk ikut serta dalam penelitian ini dengan bukti lembar persetujuan yang ditandatangani oleh pasien maupun pendamping pasien. Pengumpulan sampel penelitian dilakukan selama 1 bulan, mulai minggu ke-3 bulan September 2018 sampai dengan minggu ke-3 Oktober 2018 terhadap seluruh pasien peripartum yang menjalani sectio caesarea dengan anestesi umum maupun anestesi regional di Rumah Sakit Dr. Hasan Sadikin Bandung.

Analisis data penelitian ini merupakan suatu analisis deskriptif yang menggambarkan suhu inti preanestesi dan pascaanestesi pada pasien yang menjalani sectio caesarea dalam bentuk jumlah dan juga persentase, sedangkan untuk usia pasien digunakan nilai rerata, simpangan baku/deviasi standar (SD), median, nilai minimal, dan juga maksimal. Analisis data dilakukan menggunakan program statistical product and service solution (SPSS) for windows versi 20.0.

Setelah mendapat surat persetujuan/izin dari Komite Etik Penelitian Kesehatan Rumah Sakit Dr. Hasan Sadikin/Fakultas Kedokteran Universitas Padjadjaran, pasien/subjek yang telah sesuai dengan kriteria inklusi diberikan penjelasan tentang prosedur yang akan dijalani, kemudian menandatangani surat persetujuan (informed consent). Pasien yang menjalani sectio caesarea diukur suhu inti tubuh secara timpanik dengan termometer infrared sesaat sebelum diberikan anestesi dan sesaat setelah pasien masuk ke ruang pemulihan.

Tabel 1 Nilai Rerata dan Deviasi Standar Karakteristik Pasien Sectio Caesarea

\begin{tabular}{lccc}
\hline Karakteristik Subjek & n (\%) & Rerata (SD) & Rentang \\
\hline Usia (tahun) & $47(100)$ & $28,79(6,93)$ & $17-42$ \\
$<20$ & $4(8)$ & & \\
$20-35$ & $31(66)$ & & \\
$>35$ & $12(26)$ & & $30-150$ \\
\hline Durasi operasi (menit) & $47(100)$ & $78,30(24,345)$ & \\
\hline
\end{tabular}


Tabel 2 Gambaran Suhu Inti Tubuh Preanestesi dan Pascaanestesi pada Pasien Sectio Caesarea berdasar Usia Subjek

\begin{tabular}{cccccccc}
\hline & Total & \multicolumn{4}{c}{ Suhu Inti Tubuh $\left({ }^{\circ} \mathbf{C}\right)$} \\
\cline { 2 - 8 } Usia & Pasien & \multicolumn{4}{c}{ Preanestesi } & \multicolumn{3}{c}{ Pascaanestesi } \\
\cline { 2 - 8 } & tahun) (\%) & Rerata & SD & Rentang (Median) & Rerata & SD & Rentang (Median) \\
\hline & $47(100)$ & 35,95 & 0,67 & $33,10-37,20(36,00)$ & 35,80 & 0,59 & $33,90-37,10(35,8)$ \\
$<20$ & $4(8)$ & 36,08 & 0,69 & & 35,53 & 0,92 & \\
$20-35$ & $31(66)$ & 35,93 & 0,78 & 35,74 & 0,60 & \\
$>35$ & $12(26)$ & 35,95 & 0,31 & & 36,03 & 0,35 & \\
\hline
\end{tabular}

\section{Hasil}

Telah dilakukan pengukuran suhu inti tubuh preanestesi dan pascaanestesi pada seluruh pasien peripartum yang menjalani sectio caesarea di Rumah Sakit Dr. Hasan Sadikin Bandung pada tanggal 21 September-21 Oktober 2018. Terdapat 47 pasien yang menjalani sectio caesarea dengan usia rerata pasien adalah 28,79 dan rentang usia 17-42 tahun. Kelompok usia 20-35 tahun atau usia reproduktif ideal merupakan kelompok usia terbanyak menjalani sectio caesarea, yaitu sejumlah 31 orang (66\%). Durasi operasi pada penelitian ini berlangsung selama rerata 78,30 menit dengan rentang waktu 30 hingga 150 menit (Tabel 1).
Terdapat 4 pasien berusia 20 tahun dengan suhu inti tubuh preanestesi $36,08^{\circ} \mathrm{C}$ dan pascaanestesi $35,53^{\circ} \mathrm{C}$. Pasien berusia 20-35 tahun memiliki rerata suhu inti tubuh preanestesi $35,93^{\circ} \mathrm{C}$ dan pascaanestesi $35,74^{\circ} \mathrm{C}$. Pasien berusia lebih dari 35 tahun memiliki rerata suhu inti tubuh preanestesi $35,95^{\circ} \mathrm{C}$ dan pascaanestesi $36,03^{\circ} \mathrm{C}$ (Tabel 2).

Jenis anestesi yang diberikan pada pasien sectio caesarea adalah anestesi regional spinal pada 40 pasien $(85 \%)$ dan anestesi umum pada 7 pasien $(15 \%)$. Rerata suhu inti tubuh preanestesi adalah $35,95^{\circ} \mathrm{C}$ dan rerata suhu inti tubuh pascaanestesi $35,8^{\circ} \mathrm{C}$. Pada pasien yang diberikan anestesi regional spinal, ratarata suhu inti tubuh preanestesi $35,94^{\circ} \mathrm{C}$ dan rerata suhu inti tubuh pascaanestesi $35,79^{\circ} \mathrm{C}$,

Tabel 3 Gambaran Suhu Inti Tubuh Preanestesi dan Pascaanestesi pada Pasien Sectio Caesarea berdasar Jenis Anestesi

\begin{tabular}{lccccc}
\hline \multirow{2}{*}{ Jenis Anestesi } & \multirow{2}{*}{ Total Pasien } & \multicolumn{4}{c}{ Suhu Inti Tubuh ( $^{\circ} \mathbf{C}$ ) } \\
\cline { 2 - 6 } & & \multicolumn{2}{c}{ Preanestesi } & \multicolumn{2}{c}{ Pascaanestesi } \\
\cline { 2 - 6 } & $\mathbf{n ~ ( \% )}$ & Rerata & SD & Rerata & SD \\
\hline \multirow{3}{*}{ Umum } & $47(100)$ & 35,95 & 0,67 & 35,80 & 0,59 \\
Regional spinal & $7(15)$ & 36,01 & 0,34 & 35,83 & 0,59 \\
\hline
\end{tabular}

Tabel 4 Gambaran Karakteristik Subjek Penelitian pada Pasien Sectio Caesarea

\begin{tabular}{lccc}
\hline \multicolumn{1}{c}{ Perubahan suhu $\left({ }^{\circ} \mathbf{C}\right)$} & n (\%) & Rerata (SD) & Rentang \\
\hline & $47(100)$ & $-0,15(0,78)$ & $-2,00-2,50$ \\
Peningkatan & $17(36)$ & $0,60(0,55)$ & \\
Penurunan & $30(64)$ & $-0,58(0,53)$ & \\
\hline
\end{tabular}


Tabel 5 Gambaran Perubahan Suhu Inti Tubuh pada Pasien Sectio Caesarea Berdasarkan Jenis Anestesi

\begin{tabular}{|c|c|c|c|c|c|c|}
\hline \multirow{3}{*}{ Variabel } & \multirow{3}{*}{$\begin{array}{c}\text { Total Pasien } \\
\text { n (\%) }\end{array}$} & \multicolumn{5}{|c|}{ Perubahan Suhu Inti Tubuh } \\
\hline & & \multirow{2}{*}{ Rerata } & \multicolumn{2}{|c|}{ Peningkatan } & \multicolumn{2}{|c|}{ Penurunan } \\
\hline & & & n (\%) & Rerata & n (\%) & Rerata \\
\hline Jenis anestesi & $47(100)$ & $-0,15$ & $17(38,2)$ & 0,60 & $30(63,8)$ & $-0,58$ \\
\hline Umum & $7(14,9)$ & $-0,19$ & $1(14,3)$ & 0,70 & $6(85,7)$ & $-0,33$ \\
\hline Regional spinal & $40(85,1)$ & $-0,15$ & $16(40,0)$ & 0,59 & $24(60,0)$ & $-0,64$ \\
\hline
\end{tabular}

Tabel 6 Gambaran Perubahan Suhu Inti Tubuh pada Pasien Sectio Caesarea Berdasarkan Usia

\begin{tabular}{|c|c|c|c|c|c|c|}
\hline \multirow{3}{*}{ Variabel } & \multirow{3}{*}{$\begin{array}{c}\text { Total Pasien } \\
\text { n (\%) } \\
\end{array}$} & \multicolumn{5}{|c|}{ Perubahan Suhu Inti Tubuh } \\
\hline & & \multirow{2}{*}{ Rerata } & \multicolumn{2}{|c|}{ Peningkatan } & \multicolumn{2}{|c|}{ Penurunan } \\
\hline & & & n (\%) & Rerata & n (\%) & Rerata \\
\hline Usia (tahun) & $47(100)$ & $-0,15$ & $17(38,2)$ & 0,60 & $30(63,8)$ & $-0,58$ \\
\hline$<20$ & $4(8,5)$ & $-0,55$ & 0 & 0 & $4(100)$ & $-0,55$ \\
\hline $20-35$ & $31(66,0)$ & $-0,19$ & $10(32,3)$ & 0,75 & $21(67,7)$ & $-0,63$ \\
\hline$>35$ & $12(25,5)$ & 0,08 & $7(58,3)$ & 0,39 & $5(41,7)$ & $-0,36$ \\
\hline
\end{tabular}

sedangkan pada pasien yang diberikan anestesi umum, rerata suhu inti tubuh preanestesi $36,01^{\circ} \mathrm{C}$ dan rerata suhu inti tubuh pascaanestesi $35,83^{\circ} \mathrm{C}$ (Tabel 3).

Terdapat perubahan suhu inti tubuh pada pasien sectio caesarea dengan ratarata mengalami penurunan $0,15^{\circ} \mathrm{C}$. Jumlah pasien yang mengalami penurunan suhu inti tubuh adalah 30 orang (64\%) dengan rerata penurunan sebesar $0,58^{\circ} \mathrm{C}$ dan mengalami peningkatan sebanyak 17 orang (36\%) dengan rerata peningkatan sebesar $0,60^{\circ} \mathrm{C}$ (Tabel 4).

Rerata penurunan suhu inti tubuh pada pasien yang diberikan anestesi umum adalah $0,19^{\circ} \mathrm{C}$ dan pada pasien yang diberikan anestesi regional spinal $0,15^{\circ} \mathrm{C}$. Terdapat 1 dari 7 pasien yang mengalami peningkatan suhu sebesar $0,70^{\circ} \mathrm{C}$ dan 6 dari 7 pasien yang mengalami penurunan suhu dengan rerata $0,33^{\circ} \mathrm{C}$ pada pasien yang diberikan dengan anestesi umum. Perubahan suhu inti tubuh pada pasien yang diberikan anestesi regional spinal adalah 16 pasien (40\%) mengalami peningkatan suhu dengan rerata $0,59^{\circ} \mathrm{C}$ dan 24 pasien $(60 \%)$ mengalami penurunan suhu dengan rerata $0,64^{\circ} \mathrm{C}$ (Tabel 5).

Penurunan suhu inti tubuh pada pasien berusia kurang dari 20 tahun $0,55^{\circ} \mathrm{C}$. Pasien berusia 20-35 tahun mengalami rerata perubahan suhu inti tubuh, yaitu penurunan sebesar $0,19^{\circ} \mathrm{C}$. Terdapat rerata perubahan suhu inti tubuh, yaitu peningkatan sebesar $0,08^{\circ} \mathrm{C}$ pada pasien berusia lebih dari 35 tahun (Tabel 6).

\section{Pembahasan}

Terdapat 47 pasien yang menjalani sectio caesarea di Rumah Sakit Dr. Hasan Sadikin Bandung pada minggu ke-3 bulan September hingga minggu ke-3 bulan Oktober 2018. Rerata suhu inti tubuh pada pasien preanestesi $35,95^{\circ} \mathrm{C}$ dan pascaanestesi $35,80^{\circ} \mathrm{C}$. Nilai tersebut berada di bawah nilai normal suhu inti tubuh, yaitu $36,50-37,20^{\circ} \mathrm{C}$. Median suhu inti tubuh preanestesi $36,00^{\circ} \mathrm{C}$ dan pascaanestesi $35,80^{\circ} \mathrm{C}$. Rentang suhu inti tubuh preanestesi $33,10-37,20^{\circ} \mathrm{C}$ dan suhu inti tubuh pascaanestesi $33,90-37,10^{\circ} \mathrm{C}$. Sebagian besar suhu inti tubuh pasien preanestesi 
dan pascaanestesi berada di bawah nilai normal suhu inti tubuh. Suhu inti tubuh rendah pada pasien yang akan menjalani operasi dipengaruhi oleh faktor eksternal seperti paparan suhu ruang yang lebih rendah dibanding dengan suhu inti tubuh. Suhu inti tubuh rendah pada pasien setelah selesai menjalani operasi selain dipengaruhi oleh faktor eksternal juga dipengaruhi oleh faktor internal, yakni efek vasodilatasi pada pembuluh darah perifer akibat pemberian anestesi.

Rerata pasien mengalami perubahan suhu inti tubuh, yaitu penurunan $0,15^{\circ} \mathrm{C}$ dengan rentang penurunan $2^{\circ} \mathrm{C}$ hingga peningkatan sebesar $2,5^{\circ} \mathrm{C}$. Perubahan suhu inti tubuh merupakan hal yang dapat terjadi pada pasien yang menjalani operasi karena gangguan termoregulasi yang dialami selama pasien diberikan anestesi. Umumnya terjadi penurunan selama operasi berlangsung karena berbagai faktor eksternal yang memengaruhi. Angka penurunan suhu inti tubuh umumnya dapat mencapai $0,50^{\circ} \mathrm{C}$ setelah 30 menit pertama operasi dan terus menurun hingga $1,5^{\circ} \mathrm{C}$ setelah 1 jam karena proses redistribusi panas dari inti menuju perifer tubuh. ${ }^{2,12,13}$ Penurunan suhu inti tubuh akan terus berlangsung lebih lambat hingga menjadi stabil setelah 3-5 jam operasi. Hal tersebut terjadi karena produksi panas tubuh mulai mengimbangi proses kehilangan panas tubuh.

Perubahan suhu inti tubuh terjadi pada pasien perioperatif karena gangguan pada mekanisme termoregulasi yang dipengaruhi oleh beberapa faktor seperti jenis anestesi yang diberikan, paparan suhu ruang operasi, dan durasi operasi. ${ }^{2-5} \mathrm{Pada}$ anestesi umum terdapat gangguan pada 3 mekanisme termoregulasi, yaitu pada input aferen, pengaturan sinyal di daerah pusat, dan respons eferen, serta pergeseran batas ambang tahanan termoregulasi. Pada anestesi regional, khususnya spinal terjadi gangguan pada 2 mekanisme termoregulasi, yaitu pada input aferen dan respons eferen. ${ }^{1}$ Hal tersebut terjadi karena mekanisme kerja obat pada anestesi regional mengganggu transmisi saraf di medula spinalis sehingga terjadi pergeseran batas ambang vasokonstriksi dan respons menggigil menjadi lebih rendah daripada efek anestesi umum dan batas ambang pengeluaran keringat menjadi meningkat. ${ }^{2}$ Pergeseran batas ambang respons autonom dan respons perilaku menyebabkan jarak batas ambang melebar sehingga suhu inti tubuh pasien menjadi poikilotermik selama proses operasi berlangsung. ${ }^{15}$ Maka dari itu, pada penelitian ini didapati penurunan suhu inti tubuh sebesar $0,58^{\circ} \mathrm{C}$ pada 30 pasien yang menjalani sectio caesarea, 6 di antaranya diberikan anestesi umum dan 24 lainnya diberikan anestesi regional spinal. Pemberian anestesi dan tindakan operasi mengganggu keseimbangan panas tubuh karena faktor eksternal yang memengaruhi mekanisme redistribusi panas tubuh seperti suhu ruangan, durasi operasi, jenis operasi, suhu cairan irigasi, dan suhu cairan infus. ${ }^{16}$

Sebanyak $36 \%$ pasien mengalami peningkatan suhu inti tubuh dengan 1 orang yang diberikan anestesi umum dan 12 orang yang diberikan anestesi regional spinal. Peningkatan suhu inti tubuh pada pasien perioperatif dapat dipengaruhi oleh berbagai faktor, seperti tata laksana untuk menjaga termoregulasi selama operasi, infeksi perioperatif, ritme sirkadian pada saat pasien menjalani operasi, dan kondisi yang mengindikasikan pasien menjalani sectio caesarea. ${ }^{1,14}$ Suhu ruang operasi diatur sedemikian rupa agar suhu inti tubuh pasien tetap berada pada kondisi normotermia. Suhu ruang $>23^{\circ} \mathrm{C}$ merupakan suhu yang ideal untuk ruang operasi, jika suhu kurang dari $23^{\circ} \mathrm{C}$ maka pasien akan lebih rentan mengalami hipotermia. Suhu cairan irigasi dan cairan infus untuk pasien juga harus terjaga hangat agar tidak terjadi hipotermia pada pasien. Suhu ruang operasi, pembersihan peritoneum dengan cairan irigasi selama operasi, dan cairan infus yang dingin dapat berpengaruh pada mekanisme radiasi dan konveksi pada redistribusi panas tubuh pasien ke lingkungan. Tindakan penghangatan cairan infus dan cairan irigasi akan mengurangi laju perpindahan panas dari inti ke perifer tubuh 
sehingga suhu inti tubuh tidak berkurang secara drastis. Hal ini terjadi karena setelah pemberian anestesi akan memberikan efek vasodilatasi pada perifer yang menyebabkan panas tubuh berpindah ke lingkungan dengan cepat. Suatu penelitian menyatakan bahwa menjaga suhu ruang $>23^{\circ} \mathrm{C}$ dapat menurunkan insidensi hipotermia pada pasien yang menjalani operasi. ${ }^{17}$

Sepuluh pasien yang berusia 20-35 tahun (32\%) mengalami peningkatan suhu sebesar $0,75^{\circ} \mathrm{C}$ dan 7 pasien yang berusia lebih dari 35 tahun mengalami peningkatan suhu sebesar $0,39^{\circ} \mathrm{C}$. Peningkatan suhu pascaanestesi pada penelitian ini merupakan sebuah proses pemulihan suhu yang dipengaruhi oleh faktor eksternal seperti pengaturan suhu ruang operasi, pemberian cairan infus hangat, dan pembersihan peritoneum dengan cairan irigasi yang hangat. Terdapat penurunan besar selisih pada peningkatan suhu inti tubuh berdasar usia. Proses pemulihan suhu inti tubuh pada seseorang dapat dipengaruhi oleh usia, ${ }^{4}$ namun dalam penelitian ini tidak signifikan karena kelompok usia pada penelitian masih dalam usia dewasa muda. Proses pemulihan suhu inti tubuh mulai terganggu pada usia lanjut.

\section{Simpulan}

Semua pasien pada penelitian ini mengalami perubahan suhu inti tubuh. Lebih banyak pasien yang mengalami penurunan suhu inti tubuh dibanding dengan peningkatan suhu inti tubuh. Perubahan suhu inti dipengaruhi oleh faktor eksternal seperti jenis anestesi yang diberikan, suhu ruangan operasi, suhu cairan infus, dan suhu cairan irigasi untuk pembersihan peritoneum. Faktor eksternal tersebut membuat pasien memiliki risiko hipotermia.

\section{Daftar Pustaka}

1. John E,Hall P. Guyton and hall textbook of medical physiology. Edisi ke-13. Philadelphia: Elsevier Ltd; 2016.

2. Miller RD. Miller's anesthesia. Edisi ke-8.
Philadelphia: Elsevier Ltd; 2015.

3. Hart SR, Bordes B, Hart J, Corsino D, Harmon D. Unintended perioperative hypothermia. Ochsner J. 2011;11(3):25970.

4. Harahap AM, Kadarsah RK, Oktaliansah E. Angka kejadian hipotermia dan lama perawatan di ruang pemulihan pada pasien geriatri pascaoperasi elektif bulan Oktober 2011-Maret 2012 di Rumah Sakit Dr. Hasan Sadikin Bandung. JAP. 2014;2(1):36-44.

5. Rafii A. Body temperature during surgery and anesthesia. MCV QUARTERLY. 1972;8(2):135-41.

6. Allen TK, Habib AS. Inadvertent perioperative hypothermia induced by spinal anesthesia for cesarean delivery might be more significant than we think: are we doing enough to warm our parturients? Anesth Analg. 2018;126(1):7-9.

7. Moola S, Lockwood C. Effectiveness of strategies for the management and/or prevention of hypothermia within the adult perioperative environment. Int J Evid Based Healthc. 2011;9(4):337-45.

8. Trihono. Riset Kesehatan Dasar 2013. Jakarta; Badan Penelitian dan Pengembangan Kesehatan: 2013. hlm. 1-384.

9. Hess PE, Snowman CE, Wang J. Hypothermia after cesarean delivery and its reversal with lorazepam. Int J Obstet Anesth. 2005;14(4):279-83.

10. Munday J, Osborne S, Yates P, Sturgess D, Jones L, Gosden E. Preoperative warming versus no preoperative warming for maintenance of normothermia in women receiving intrathecal morphine for cesarean delivery: a single-blinded, randomized controlled trial. Anesth Analg. 2018;126(1):183-9.

11. Duryea E, Nelson D, Wyckoff M, Grant E, Tao W. The impact of ambient operating room temperature on neonatal and maternal hypothermia and associated morbidities: a randomized controlled trial. Am J Obstet Gynecol. 2016;214(4):505.e1-e7.

12. Perlman J, Kjaer K. Neonatal and maternal 
temperature regulation during and after delivery. Anesth Analg. 2016;123(1):16872.

13. Woolnough M, Allam J, Hemingway C, Cox M, Yentis SM. Intra-operative fluid warming in elective caesarean section: a blinded randomised controlled trial. Int J Obstet Anesth. 2009;18(4):346-51.

14. Obi VO, Umeora OU J. Anesthesia for emergency cesarean section: a comparison of spinal versus general anesthesia on maternal and neonatal outcomes. Afr J Med Health Sci. 2018;17:31-4.
15. Sessler D. Temperature monitoring and perioperative thermoregulation. Anesthesiology. 2008;109(2):318-38.

16. Kurz A. Physiology of thermoregulation. Best Pract Res Clin Anaesthesiol. 2008;22(4):627-44.

17. Cobb B, Cho Y, Hilton G, Ting V, Carvalho B. Active warming utilizing combined iv fluid and forced-air warming decreases hypothermia and improves maternal comfort during cesarean delivery: a randomized control trial. Anesth Analg. 2016;122(5):1490-7. 